\title{
Article \\ Coordinated Control of Diesel Generators and Batteries in DC Hybrid Electric Shipboard Power System
}

\author{
Luona Xu (D), Baoze Wei, Yun Yu, Josep M. Guerrero *(D) and Juan Vasquez $(D)$ \\ The Villum Center for Research on Microgrids (CROM), AAU Energy, Aalborg University, \\ 9220 Aalborg, Denmark; lxu@energy.aau.dk (L.X.); bao@energy.aau.dk (B.W.); yyu@energy.aau.dk (Y.Y.); \\ juq@energy.aau.dk (J.V.) \\ * Correspondence: joz@energy.aau.dk
}

\section{check for} updates

Citation: Xu, L.; Wei, B.; Yu, Y.; Guerrero, J.M.; Vasquez, J. Coordinated Control of Diesel Generators and Batteries in DC Hybrid Electric Shipboard Power System. Energies 2021, 14, 6246. https://doi.org/10.3390/en14196246

Academic Editors: Luis

M. Fernández-Ramírez,

Francisco Jurado, Luis Sainz-Sapera and Maria Carmela Di Piazza

Received: 17 July 2021

Accepted: 24 September 2021

Published: 1 October 2021

Publisher's Note: MDPI stays neutral with regard to jurisdictional claims in published maps and institutional affiliations.

Copyright: (c) 2021 by the authors. Licensee MDPI, Basel, Switzerland. This article is an open access article distributed under the terms and conditions of the Creative Commons Attribution (CC BY) license (https:// creativecommons.org/licenses/by/ $4.0 /)$.

\begin{abstract}
Hybrid electric ships powered by diesel generators and batteries are the main configuration for shipboard microgrids (SMGs) in the current maritime industry. Extensive studies have been conducted for the hybrid operation mode, whereas the all-electric operation mode and the switching between the aforementioned two modes in a system with multiple generators and batteries have not been tested. In this paper, a coordinated approach for a hybrid electric ship is proposed, where two operation modes have been simultaneously considered. More specifically, for achieving an efficient operation with reduced generator wear losses, the governor-less diesel-engine-driven generators have been adopted in the study. According to the practical operation conditions, two operation modes, the all-electric and hybrid modes, are preset. Based on these, the coordination of the generators acting as the main power sources and batteries regulating the power flow and improving the generator efficiency is studied. The governor-less diesel generators are regulated to inject the rated power in order to maximize the generator efficiency, while the DC bus voltage is regulated by DC/DC converters. For the benefit of the overall lifespan of battery banks, power sharing during charging and discharging states have been realized by the state of charge (SoC)-based adaptive droop regulator. For the test of two operation modes, as well as the mode switching, a simulation assessment in a $1 \mathrm{kV}$ DC SMG has been conducted. The simulation results show that the DC bus voltage can be controlled well, and that the power sharing among batteries follows the design. Additionally, smooth transients can be observed during mode switching when the proposed control scheme is applied.
\end{abstract}

Keywords: hybrid electric ship; DC shipboard microgrid; coordinated control; battery energy storage system; diesel generator; state of charge

\section{Introduction}

The maritime industry is developing an integrated power system (IPS) for hybrid and all-electric ships [1]. The IPS allows for the electrification of the propulsion system, therefore enabling a more flexible operation [2]. Among the IPSs, the DC distribution networks attract more attention compared with the AC networks, for various benefits provided from the aspects of manipulability, flexibility, energy efficiency, and environmental impacts [3]. On the other hand, the electric propulsion motors, high power radar, and even the electromagnetic guns in naval ships introduce many challenges in the shipboard microgrid (SMG) design. The propulsion motors consume approximately $80 \%$ of the total generation capacity [4], and pulsed loads require a high transient power, which may affect the system stability [5]. To achieve a supply-demand balance, power sources with a large energy capacity and high power density are required in a DC SMG. Diesel generators are common energy sources, not only in conventional configured ships but also in advanced hybrid electric ships, providing high energy [6,7]. Considering the shipboard load demands with fast dynamics, the energy storage system (ESS) is usually integrated into a DC SMG to compensate for the transient power. Currently, there are several types of ESSs potentially suitable for DC SMGs, mainly including the Li-ion batteries [7,8], ultra-capacitors 
(UCs) $[9,10]$, and flywheels [11,12]. Among them, batteries have the merits of a relatively high energy density, whereas UCs and flywheel ESSs can discharge with a high transient power. Therefore, hybrid ESSs (HESSs) consisting of more than two different types of energy storage units attract much attention [13]. A comparison of different HESSs is presented in [14], studying the optimal combination of energy storage units for minimizing the voltage fluctuations caused by pulsed loads. The results show that a HESS consisting of a battery and flywheel has a better performance, whereas the effect of UC is not so significant in mitigating the voltage fluctuation.

In order to coordinate different power sources in the DC SMG, numerous studies and approaches are taken in the literature. The coordinated control objectives include mitigating the transient voltage fluctuation when the load changes, achieving the economic dispatch of power sources, and improving the fuel efficiency [15-19]. Depending on the system configuration and control objectives, different coordinated control approaches can be implemented. Since the generators are connected to the DC bus through controllable rectifiers, it is possible to regulate the generator speed without affecting the DC-link voltage. This configuration enables the generator to minimize the fuel consumption by varying the rotation speed according to the load profile $[20,21]$. Therefore, one approach to managing the power is to predesign the generator power according to the load profile and battery states. A coordinated control strategy for fuel saving in a hybrid electric tugboat is presented in [19], in which the diesel generator provides the majority of loads, and the battery takes the responsibility of compensating the power mismatch between the loads and generator power. The bus voltage is regulated by the battery controller. Similarly, another study case based on a hybrid electric boat with two diesel generators and one battery is studied in [7], and the DC bus voltage is managed by the rectifier controller on the generator side. Besides the generators and ESS, fuel cells are studied to fit the application of DC SMGs. In [22], a medium-voltage DC SMG in which the power sources consist of two generators, one battery and one fuel cell, is studied. In this system, the DC bus voltage is controlled by the DC/DC converters in the battery and fuel cell sides, and the generators regulate the output power by regulating the speed and excitation current. However, these approaches require regulating the engine speed and, therefore, the generator power is lower than the rated value during much of the operation time, resulting in a reduced efficiency. In addition, for naval ships equipped with high power pulsed loads, the power system control is more complicated with HESS. Since UC and flywheel ESS could generally discharge with a higher power ramp rate than the battery, power sharing for a HESS consisting of a battery and UC or flywheel can be achieved by allocating the high-frequency load demand to the UC or flywheel ESS, while allocating the low-frequency load demand to the battery $[23,24]$.

However, in the aforementioned literatures, the all-electric operation mode, which is the trend of future electric ships, is not included in the studies. The all-electric mode can be activated when the ESS can meet the shipboard load demand, or when the ship berth is at the shore and the engines are turned off for fuel saving and reducing the noise while lacking a charger to supply the shipboard loads. In addition, the switching between all-electric mode and hybrid mode has not been tested in the DC SMG, and the corresponding transients during mode switching lack investigation. In order to satisfy the potential requirements in different operation modes of DC SMG and to study the system responses during the operation mode switching, this paper fully considers the practical operation conditions and studies the coordinated control strategy for a hybrid electric ship with two governor-less diesel generators and two battery packs as the shipboard power sources. The effectiveness of the corresponding control strategy in ensuring the efficiency of diesel generators and balancing the $\mathrm{SoC}$ of the batteries and smooth transients has been demonstrated in the simulation studies, where different operation modes and mode switching have been simultaneously included.

This paper is organized as follows: an overview of the DC SMG architecture and the operation principle is introduced in Section 2. In Section 3, the coordinated control strategy, 
including the controller design in the generator side and battery side, is presented. Section 4 shows the simulation results of the proposed coordinated control strategy. Section 5 gives the conclusions of this work.

\section{System Configuration}

\subsection{Architecture of DC SMG}

The DC SMG architecture is designed as a zonal configuration according to the recommendation of IEEE Std. 1709-2010 [25]. Compared with the conventional radial configuration, the zonal design provides a higher reliability and survivability by connecting the load centers with two interfaces. In this paper, the DC SMG consists of two diesel generator sets, two battery ESSs (BESSs), and several electric propulsion systems, and the shipboard loads are studied. The system configuration is shown in Figure 1a. The governor-less diesel-engine-driven synchronous generators (SGs) are connected to the DC bus through active rectifiers, and the lithium batteries are connected through the bidirectional DC/DC converters. Though the rectifier on the generator side is assumed to be unidirectional, the active rectifier is used in many cases for the benefits provided from the aspects of voltage control, power quality regulation, and fault management $[9,21,26]$. In the zonal DC SMG, the shipboard loads are allocated as several zonal load centers longitudinally, along with the hull, and each load center has two interfaces to the $1 \mathrm{kV}$ DC bus, therefore enhancing the power supply continuity. Since this paper focuses on the coordination of the generation side, it is acceptable to use the simplified architecture shown in Figure 1b.

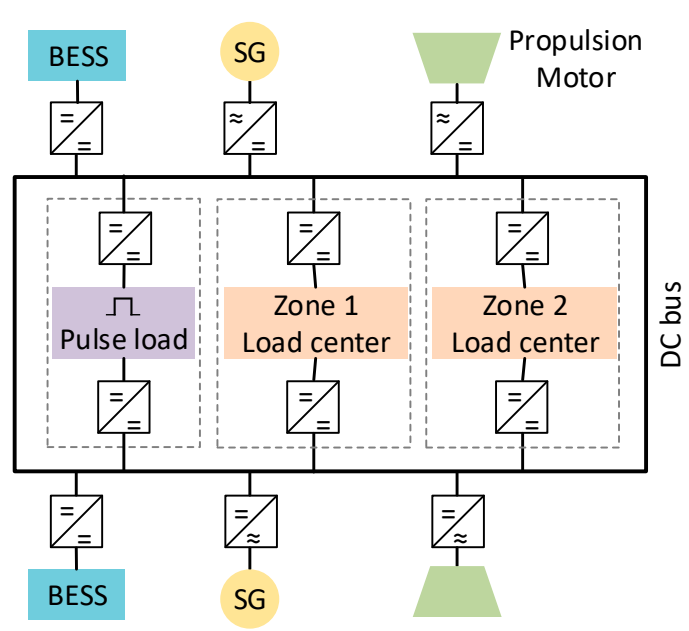

(a)

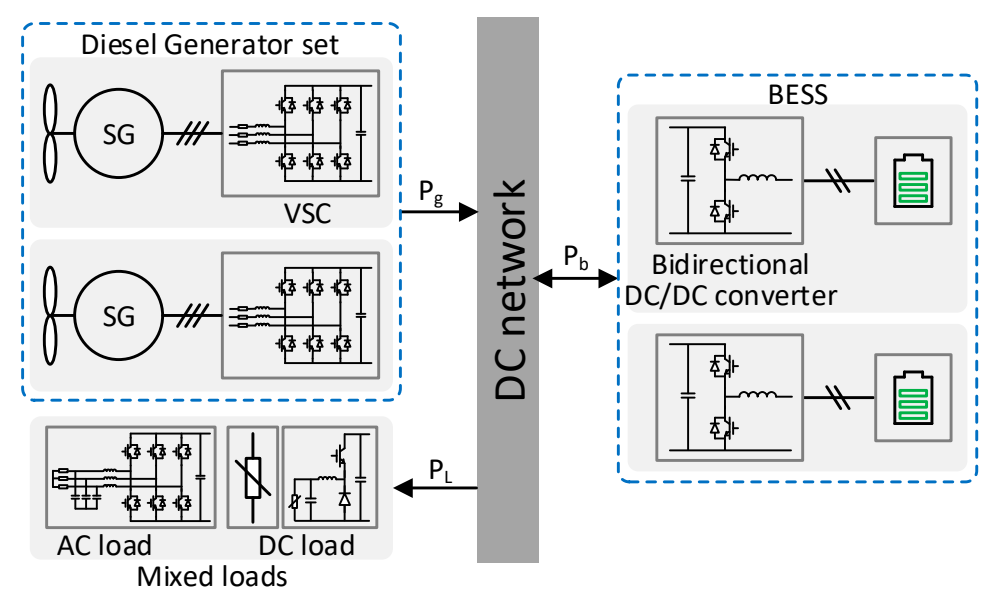

(b)

Figure 1. Configuration of a DC SMG: (a) typical configuration recommended by IEEE Std. 1709-2010; (b) simplified architecture of a DC SMG $\left(P_{\mathrm{g}}, P_{\mathrm{b}}\right.$, and $P_{\mathrm{L}}$ are the output power from generators, charge/discharge power from BESS, and load power, respectively).

In the simulation model, the governor-less diesel-engine-driven SGs are represented by SGs with a constant excitation current reference and constant torque reference, both of which are 1 p.u. in order to generate the rated power. The rated generator power is $75 \mathrm{~kW}$, the maximum discharging power of the battery $P_{\mathrm{b}_{-} \mathrm{d}}$ is $60 \mathrm{~kW}$, and the maximum charging power of the battery $P_{\mathrm{b}_{-} \mathrm{c}}$ is $30 \mathrm{~kW}$. The maximum generation power of the system is $270 \mathrm{~kW}$. Due to the presence of pulsed loads with a high power ramp rate, the ESS becomes the main power supply. Therefore, the rated power of the ESS is designed to be close to that of the generator in this study. 


\subsection{Operation Principle}

The main objective of the presented operation principle is to maximize the generator efficiency and extend the lifetime with the coordination of the BESS. Normally, the diesel engines have a maximum efficiency at the rated power. Thus, the diesel generators are designed to operate at the maximum efficiency point and generate a constant electric power [27]. The benefit of integrating the BESS is allowing for the generator to operate at the maximum efficiency point. Even though the variable-speed generator under energy management system control provides a good performance in fuel saving, the generator wear is ignored, especially in cases of dramatic fluctuating loads, which may consequently require the generator speed to change frequently. However, frequent speed changes result in excessive mechanical wear and tear in the generator set, reducing the system's lifetime.

Therefore, the proposed operation principle simplifies the generator speed regulation by adopting a governor-less engine to drive the SG instead, and regulates the charging and discharging of the BESS according to the load profile and battery SoC. The mode switching criteria are presented in Figure 2. Note that, in this paper, the positive direction is defined as the battery current/power flow out of the BESS.

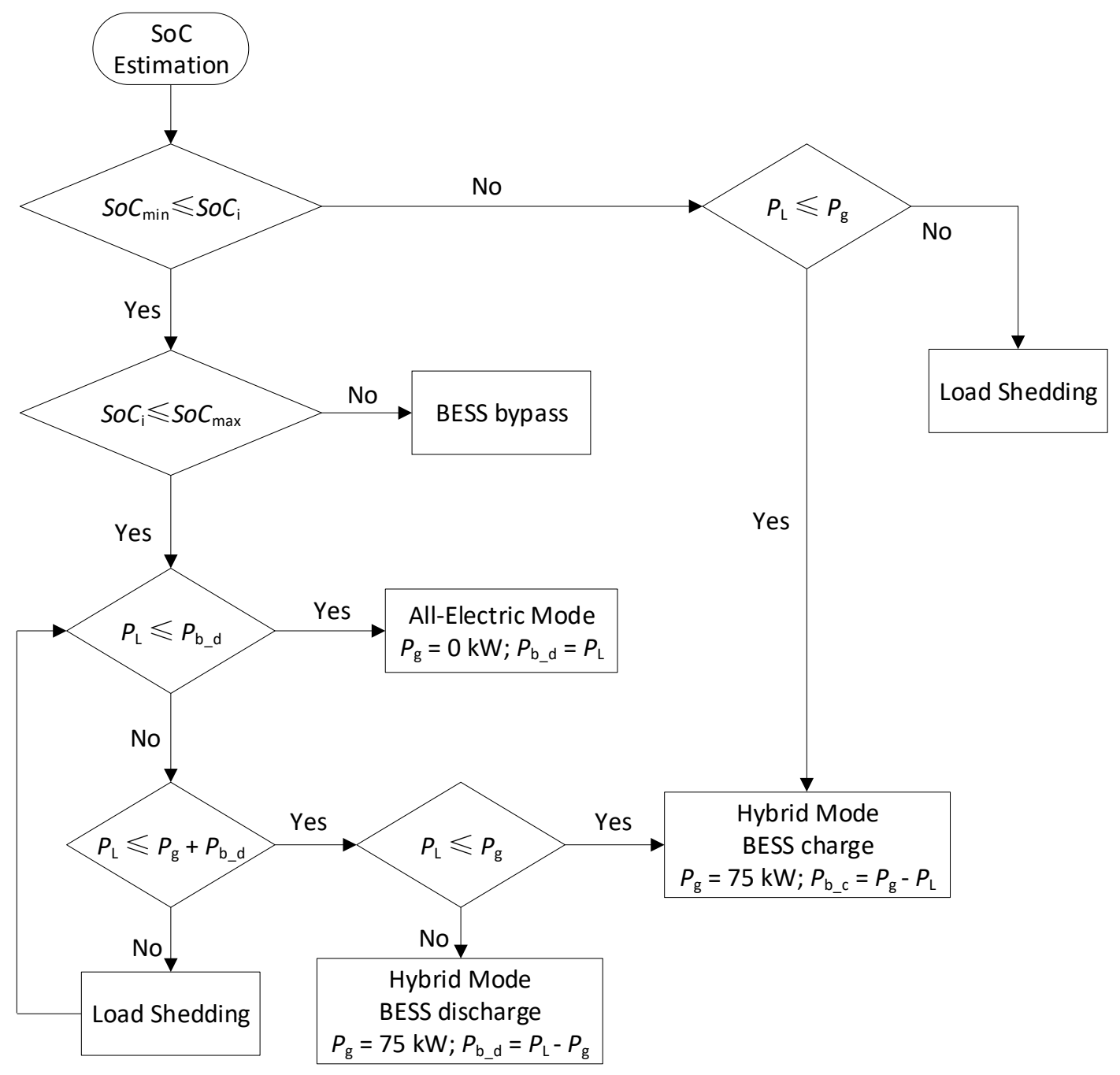

Figure 2. Flowchart for the selection of different operation modes.

The operation modes are clarified as follows:

(1) All-electric mode. In this operation mode, the diesel generators are turned off, and the BESSs are the only power sources for the shipboard loads. This operation mode applies to a short-distance voyage, and the light load conditions dictate that the load 
demand is less than the BESS output power when the battery SoC is higher than the minimum value $\mathrm{SoC}_{\min }$. In addition, the all-electric mode can be activated and the batteries are charged when the ship is docked at harbor, which is also called 'cold ironing';

(2) Hybrid mode. In this operation mode, both diesel generators and BESSs are connected to the DC SMG. The generators are designed to both operate at a rated speed and output the rated power so that the efficiency can reach the maximum, as the manufacturer desired. When the load power is lower than the rated power of multiple generators and the battery $\mathrm{SoC}$ is lower than its maximum value $\mathrm{SoC}_{\max }$, the surplus power can be charged into the BESS, whereas, when the load demand exceeds the rated generator power, the BESS discharges the mismatch between the load demand and generator power until the battery $\mathrm{SoC}$ reaches $\mathrm{SoC}_{\min }$. Besides, load shedding is required when the system is overloaded. This operation mode can be activated when the ship sails over long distances and the ESS cannot fully support the load demand. Besides, the hybrid mode is required when the shipboard ESS is fully discharged.

\section{Coordinated Control Strategy}

The energy flow in the DC SMG is managed by the coordination method of converters. In the islanded DC SMG, the change in the DC-link voltage of the power converters reflects the unbalance between the generation side and the load side. Therefore, the DC bus voltage is a trigger of power changes. This section focuses on the converter-level control, in which the coordinated control objects ensure that the DC bus voltage is within an acceptable range and shares the load as designed, while the system-level control, known as the energy management system (EMS), regulates the power of each converter with specific optimization objectives.

There are two main control objectives in the coordinated control of DC SMG: (1) regulating the DC bus voltage; (2) sharing the load among the power sources properly. For the normal operation of a DC SMG, the DC bus voltage has to be maintained around the rated value, with a limited variation under both operation modes. As the two generation sets and two BESSs share the same parameters, respectively, they are desired to share the loads equally. In this section, the control scheme for achieving these two control objectives in all-electric and hybrid modes is presented.

\subsection{BESS and DC/DC Converter Control}

The BESSs are integrated into the system through the bidirectional DC/DC converters. In order to prolong the lifetime of BESSs and avoid the overuse of one certain unit, it is necessary to balance the state of charge (SoC) of two batteries. The battery SoC can be estimated through the coulomb counting method, as shown in Equation (1):

$$
\operatorname{SoC}_{i}=\operatorname{SoC}_{i}\left(t_{0}\right)-\frac{1}{C_{\text {ratedi }}} \int\left(i_{b i}+I_{s i}\right) d t
$$

where $S_{o} C_{i}\left(t_{0}\right)$ is the initial SoC of battery $\# i, C_{\text {ratedi }}$ is the nominal capacity of the battery (Unit: As), $i_{b i}$ is the battery output current, and $I_{\mathrm{s} i}$ is the self-discharging rate. In this paper, the positive battery current means the battery is discharging, and the negative battery current means the battery is charging.

As the BESSs are connected to the DC bus in both the all-electric mode and hybrid mode, it is reasonable to control the DC bus voltage through DC/DC converters. To avoid the over-charge and over-discharge of two batteries, it is vital to balance their SoCs. A SoC-based adaptive droop control is used in DC/DC controller. The general droop control in DC microgrids is shown in Equation (2):

$$
u_{d c i}^{r e f}=U_{d c}^{*}-R_{d i} \cdot i_{b i}
$$


in which $u_{\mathrm{dc} i}{ }^{r e f}, R_{d i}$, and $i_{b i}$ are the output voltage reference of DC/DC converter $\# i$, the droop coefficient, and the battery output current. $U_{d c}{ }^{*}$ is the nominal DC bus voltage.

In the DC SMGs, the cable length is limited, and the line impedance can be neglected. Therefore, the output voltage of the paralleled connected DC/DC converters are equal, making the output current inversely proportional to the droop coefficient, as shown in Equation (3):

$$
i_{b 1}: i_{b 2}=\frac{1}{R_{d 1}}: \frac{1}{R_{d 2}}
$$

In order to balance the $\mathrm{SoC}$, the droop coefficient is determined by the battery $\mathrm{SoC}$ and the charging/discharging state. The basic principle is that making the battery with a higher SoC injects a lower current when in charging mode and an output with a higher current in discharging mode. A SoC-based droop coefficient adjusting method is implemented in this paper. When the BESS is charged, $i_{b}<0$, the charging current is designed to be inversely proportional to the SoC; whereas when the BESS discharges, $i_{b}>0$, the discharging current is designed to be proportional to the SoC. Thus, $R_{d i}$ can be expressed as Equation (4) [28]. The SoC-based droop control is demonstrated in Figure 3.

$$
R_{d i}=\left\{\begin{array}{cc}
\frac{m_{\text {disc }}}{\operatorname{SoC}_{i}{ }^{n}} & , i_{b}>0 \\
m_{c h} \cdot S o C_{i}{ }^{n} & , i_{b}<0
\end{array}\right.
$$

in which $m_{\text {disc }}$ and $m_{c h}$ are constants for the cases of discharging and charging, respectively, and $n$ is the exponent of SoC, regulating the SoC balancing speed. The restriction of selecting $n$ is $n>0$. However, considering the tolerance of the voltage drop in certain conditions, the selection of $n$ is further limited [28]. In this paper, $n$ is selected to be 6 [28].

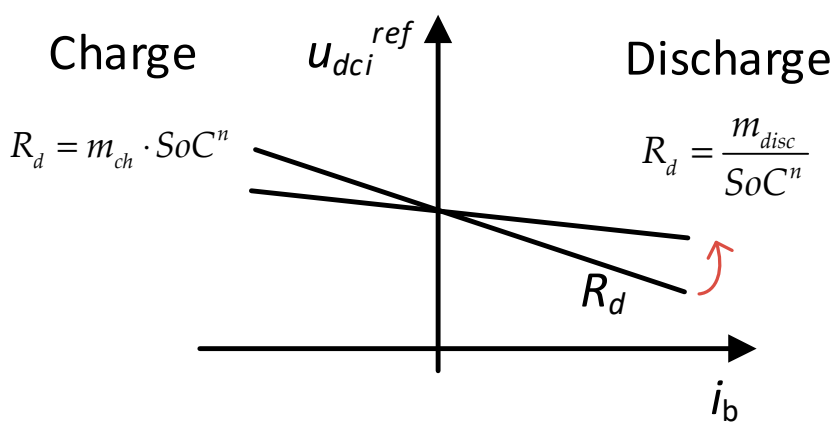

Figure 3. SoC-based droop control used in the DC SMG.

For the better understanding of the SoC balancing of applying the SoC-based adaptive droop control, the numeric solution of SoC is depicted in Figure 4, where the SoC is calculated by the coulomb counting method, i.e., Equation (1).

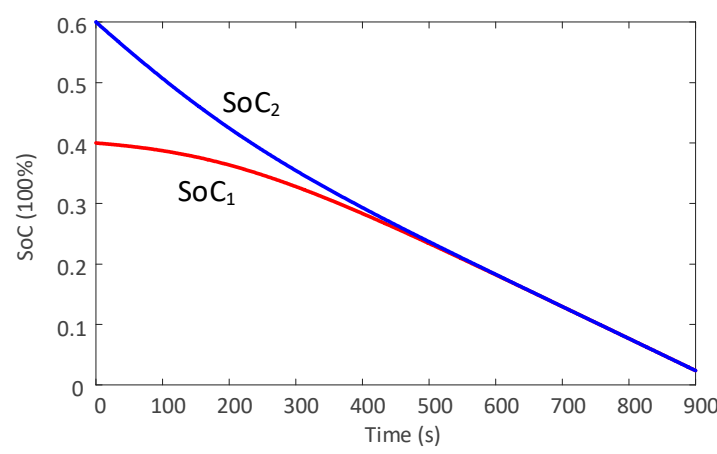

(a) Discharge mode

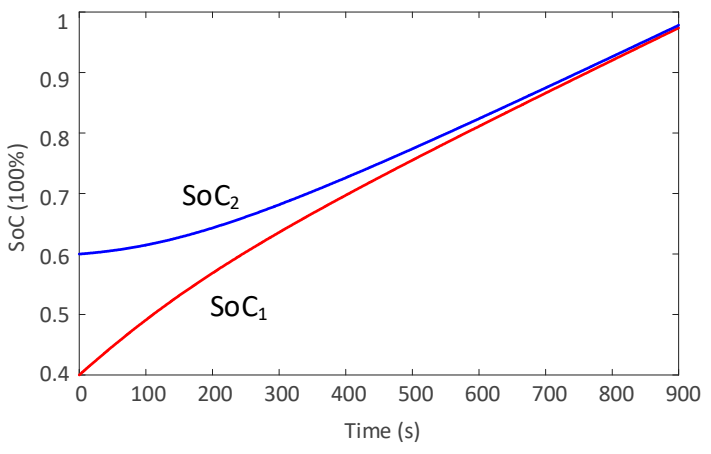

(b) Charge mode

Figure 4. Numeric solution of $\operatorname{SoC}(n=6)$. 
The parameters used for drawing Figure 4 are shown in Table 1 . The operation condition of Figure $4 \mathrm{a}$ is battery discharging, which means $i_{b i}>0(\mathrm{i}=1,2)$, whereas the operation condition of Figure $4 \mathrm{~b}$ is battery charging, which means $i_{b i}<0(\mathrm{i}=1,2)$.

Table 1. Battery parameters for SoC estimation.

\begin{tabular}{llllll}
\hline $\mathrm{SoC}_{1}\left(t_{0}\right)$ & $40 \%$ & $C_{\text {rated1 }}$ & $50 \mathrm{Ah}$ & $I_{\mathrm{s} 1}$ & $0 \mathrm{~A}$ \\
\hline $\mathrm{SoC}_{2}\left(t_{0}\right)$ & $60 \%$ & $C_{\text {rated2 }}$ & $50 \mathrm{Ah}$ & $I_{\mathrm{s} 2}$ & $0 \mathrm{~A}$ \\
\hline
\end{tabular}

For the droop-controlled DC SMG, the primary control is not able to restore the voltage after the load variation [29]. Thus, in order to eliminate the voltage mismatch, a second control can be applied for the voltage restoration, and Equation (2) becomes

$$
u_{d c i}^{r e f}=U_{d c}^{*}-R_{d i} \cdot i_{b i}+\Delta \delta_{i}
$$

where $\Delta \delta_{i}$ (unit: $\mathrm{V}$ ) is the correction term generated by the secondary controller, $U_{d c}{ }^{*}$ is the rated DC bus voltage. In this paper, the secondary controller consists of a PI controller, which can be expressed as:

$$
\Delta \delta_{i}=K_{s p} \cdot\left(U_{d c}^{*}-u_{d c i}\right)+K_{s i} \int\left(U_{d c}^{*}-u_{d c i}\right) d t
$$

The control scheme diagram is presented in Figure 5. The bidirectional DC/DC converter controller consists of the primary and secondary control. The primary controller consists of dual control loops. The outer loop is the voltage control loop, of which, the voltage reference is generated by Equations (4) and (6). The error between the voltage reference and measured voltage is the input of the PI controller. The generated current reference goes to the inner current control loop in order to generate the duty cycle $D_{i}$ of the DC/DC converter. The secondary controller employs the DC bus voltage as the feedback to compensate for the voltage deviation.

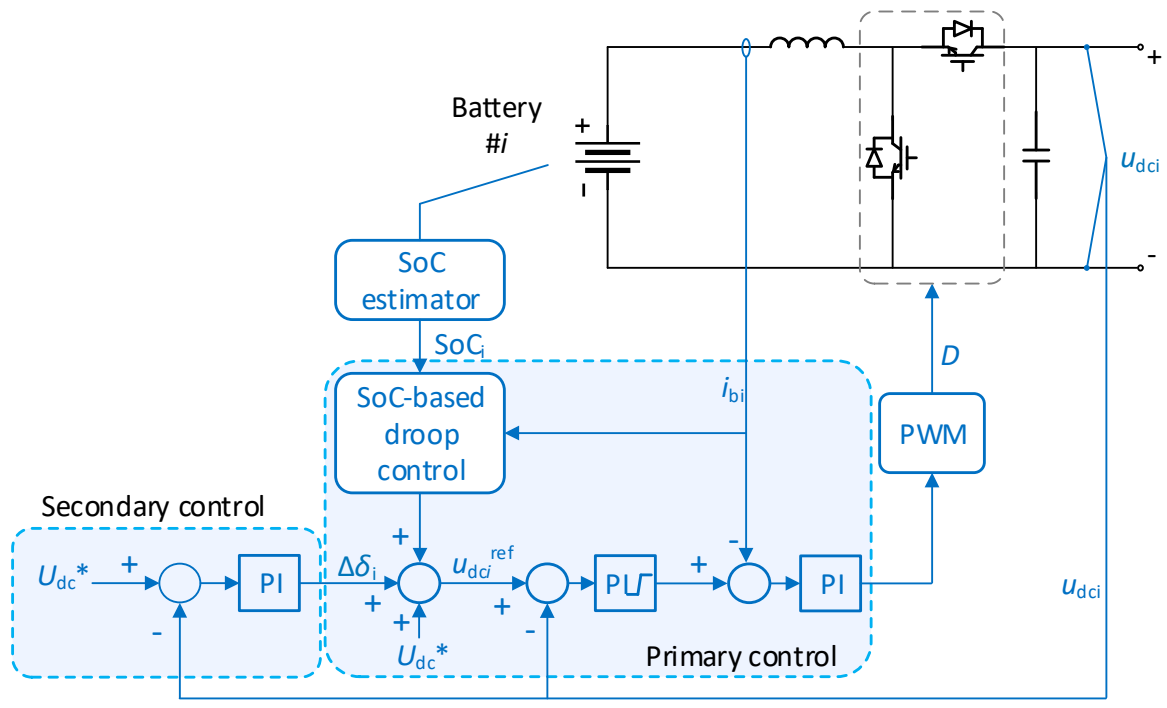

Figure 5. Control scheme of DC/DC converter.

For control parameter tuning, the overall control scheme can be simplified as shown in Figure 6, where the inner current control loop is represented by a first-order system $\left(\frac{1}{1+s T_{d}}\right)$ due to the high bandwidth [30]. In this way, the analysis can be applied for the tuning voltage and power control loops with slow dynamics. The inner current loop delay is taken as $T_{\mathrm{d}}=0.002 \mathrm{~s}$. 


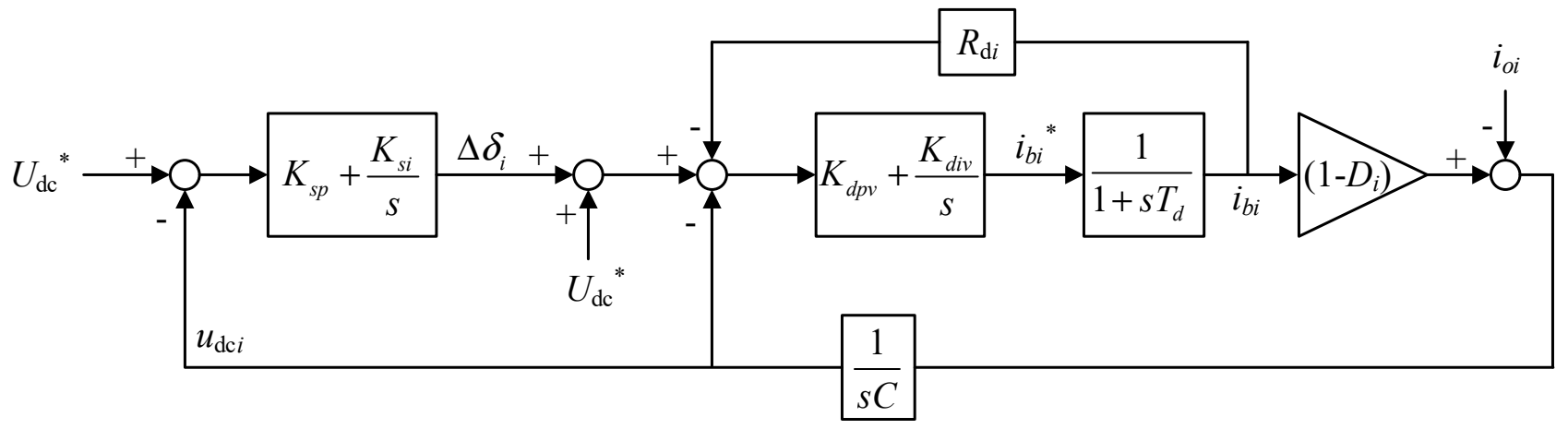

Figure 6. Control loop modelling of DC/DC converter.

Firstly, the voltage loop need to be stable, and the open-loop small-signal transfer function can be derived as [31]:

$$
G_{v}(s)=\left(K_{d p v}+\frac{K_{d i v}}{s}\right) \cdot \frac{1}{1+s T_{d}} \cdot \frac{u_{b a t i}}{u_{d c i}} \cdot \frac{1}{s C}
$$

The dynamic dependence of the output voltage on the $\Delta i_{b i}$ signal change is obtained [31]:

$$
\frac{\Delta u_{d c i}(s)}{\Delta i_{b i}(s)}=\frac{u_{b a t i}}{u_{d c i}} \cdot \frac{1}{s C}=\frac{K_{1}}{1+s T_{1}}
$$

where $K_{1}$ and $T_{1}$ are the coefficients of the averaged DC/DC converter model, and $K_{\mathrm{dpv}}$ and $K_{d i v}$ are PI controller coefficients. The corresponding bode plot is shown in Figure 7a. As indicated, there is enough of a phase margin to ensure the stability of the voltage loop.
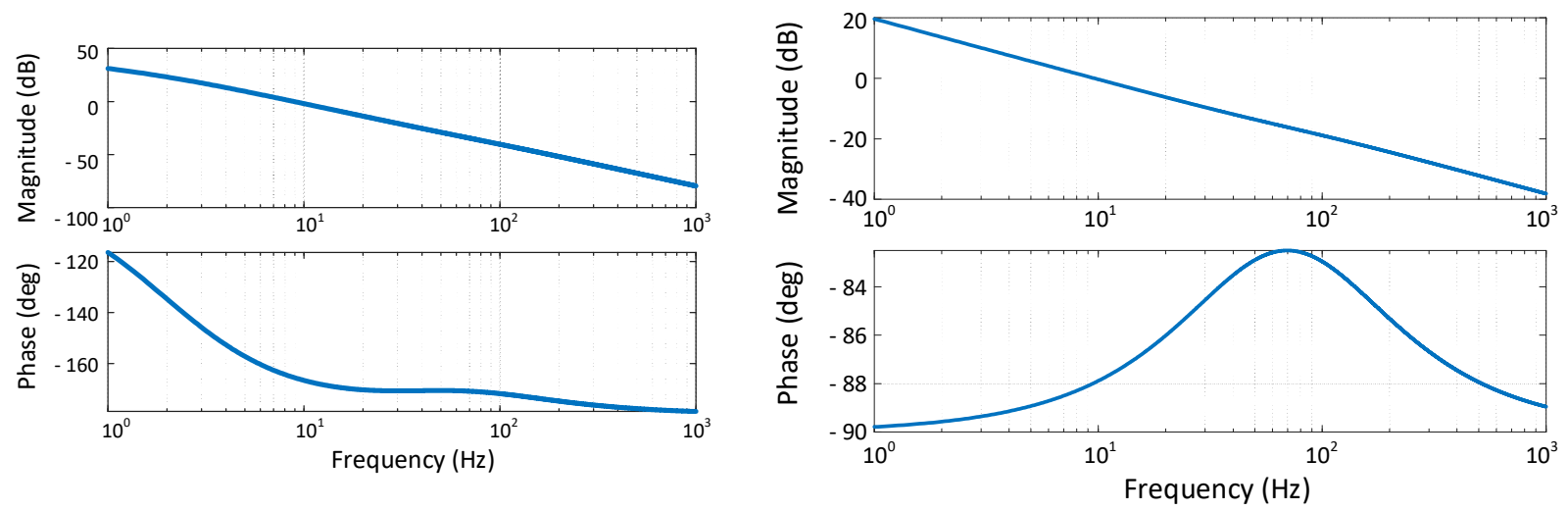

(a) Bode plot of $G_{v}(s)$

(b) Bode plot of $G$ droop (s)

Figure 7. Bode plots $\left(K_{1}=0.85 \Omega, T_{1}=0.08 \mathrm{~s}, K_{\mathrm{dpv}}=0.78 \mathrm{~A} / \mathrm{V}, K_{\mathrm{div}}=3000 \mathrm{~A} / \mathrm{Vs}\right.$ and $\left.R_{\mathrm{di}}=0.2 \Omega\right)$.

Then, the stability of the SoC-based droop control loop is checked based on the most critical SoC-based droop coefficient, since the voltage control parameters must ensure the stability of this loop in the case of any SoC value. The open-loop small-signal transfer function represents this control loop and can be obtained from Figure 6 as Equation (9), and the corresponding bode plot is shown in Figure $7 \mathrm{~b}$. As can be observed, the stability of this SoC-based droop control loop can also be stable.

$$
G_{\text {droop }}(s)=R_{d i} \cdot\left(K_{d p v}+\frac{K_{d i v}}{s}\right) \cdot \frac{1}{1+s T_{d}}
$$


Regarding the stability of the power control loop, once the inner loops can be stable, the bandwidth of the power control loop can be set to between $50 \%$ and $10 \%$ of the voltage loop's bandwidth in order to achieve acceptable stability and dynamics.

\subsection{Diesel Generator and Rectifier Control}

The governor-less diesel-engine-driven SGs connect to the DC bus through active rectifiers. In the case of the hybrid mode, the diesel generators are desired to operate at a rated speed, and the generators output the rated power so that the maximum efficiency is achieved.

In hybrid mode, the diesel generators are the main power sources, and the active power reference is dedicated to the rated power, whereas the BESSs are responsible for controlling the DC bus voltage and balancing the supply-demand by charging and discharging.

Neglecting the power losses of the rectifier, the power balance of the DC and AC sides of rectifier is expressed as [32]:

$$
u_{d c} i_{g}=\frac{3}{2}\left(u_{g d} i_{d}+u_{g q} i_{q}\right)
$$

where $u_{g d}, u_{g q}, i_{d}$, and $i_{q}$ are the generator terminal voltage and current in the $d-q$ reference frame, $u_{d c}$ is the DC-link voltage of rectifier, and $i_{g}$ is the output current of rectifier. According to the synchronous generator model in the stator flux reference frame, which is shown as follows:

$$
\begin{aligned}
& u_{g d}=R_{s} i_{d}+\frac{d \psi_{d}}{d t}-\omega_{s} \psi_{q} \\
& u_{g q}=R_{s} i_{q}+\frac{d \psi_{q}}{d t}+\omega_{s} \psi_{d}
\end{aligned}
$$

where $R_{s}$ is the stator resistance, $\psi_{d}$ and $\psi_{q}$ are $d$ - $q$ axes stator flux linkages, and $\omega_{s}$ is the electrical speed.

The electromagnetic torque and speed of the synchronous generator are expressed as:

$$
\begin{gathered}
T_{e}=\frac{3}{2} p\left(\psi_{d} i_{q}-\psi_{q} i_{d}\right) \\
J \frac{d \omega_{r}}{d t}=T_{s h}-B \omega_{r}-T_{e}
\end{gathered}
$$

where $J$ is the inertia value, $p$ is the generator pole pairs, $\omega_{r}$ is the generator speed, $T_{s h}$ is the shaft torque, $B$ is the material damping, and $T_{e}$ is the generator torque.

With the generator model, Equation (10) can be derived as

$$
\begin{aligned}
u_{d c} i_{g}+\frac{1}{2} C \frac{d^{2} u_{d c}}{d t^{2}} & =\frac{3}{2}\left(i_{d}^{2}+i_{q}^{2}\right) \cdot\left(R_{s}+R_{f}\right)+T_{e} \omega_{r} \\
\frac{d E_{c a p}}{d t} & =P_{e m}-P_{\text {load }}-P_{\text {loss }}
\end{aligned}
$$

where $E_{\text {cap }}$ is the stored energy in the DC-link capacitor, and $P_{e m}, P_{\text {load }}$, and $P_{\text {loss }}$ are the electromagnetic power, load power, and power losses, respectively. Here, $P_{e m}$ is equal to the active power reference for the rectifier controller.

The rectifier and its controller scheme are shown in Figure 8. The controller is enabled when the SMG operates in hybrid mode. A dual-loop control scheme is implemented, which consists of the outer power loop and inner current loop. In hybrid mode, the active power is dedicated to the rated power, and the reactive power is fixed to zero in order to achieve the unitary power factor. The parameters can be adjusted according to conventional linear control theory, where the open-loop bandwidth of the current control is firstly set to around $1160 \mathrm{rad} / \mathrm{s}$ for fast current regulation. For the power control, the bandwidth is set to around $35 \%$ of the inner current control loop for acceptable dynamics. 


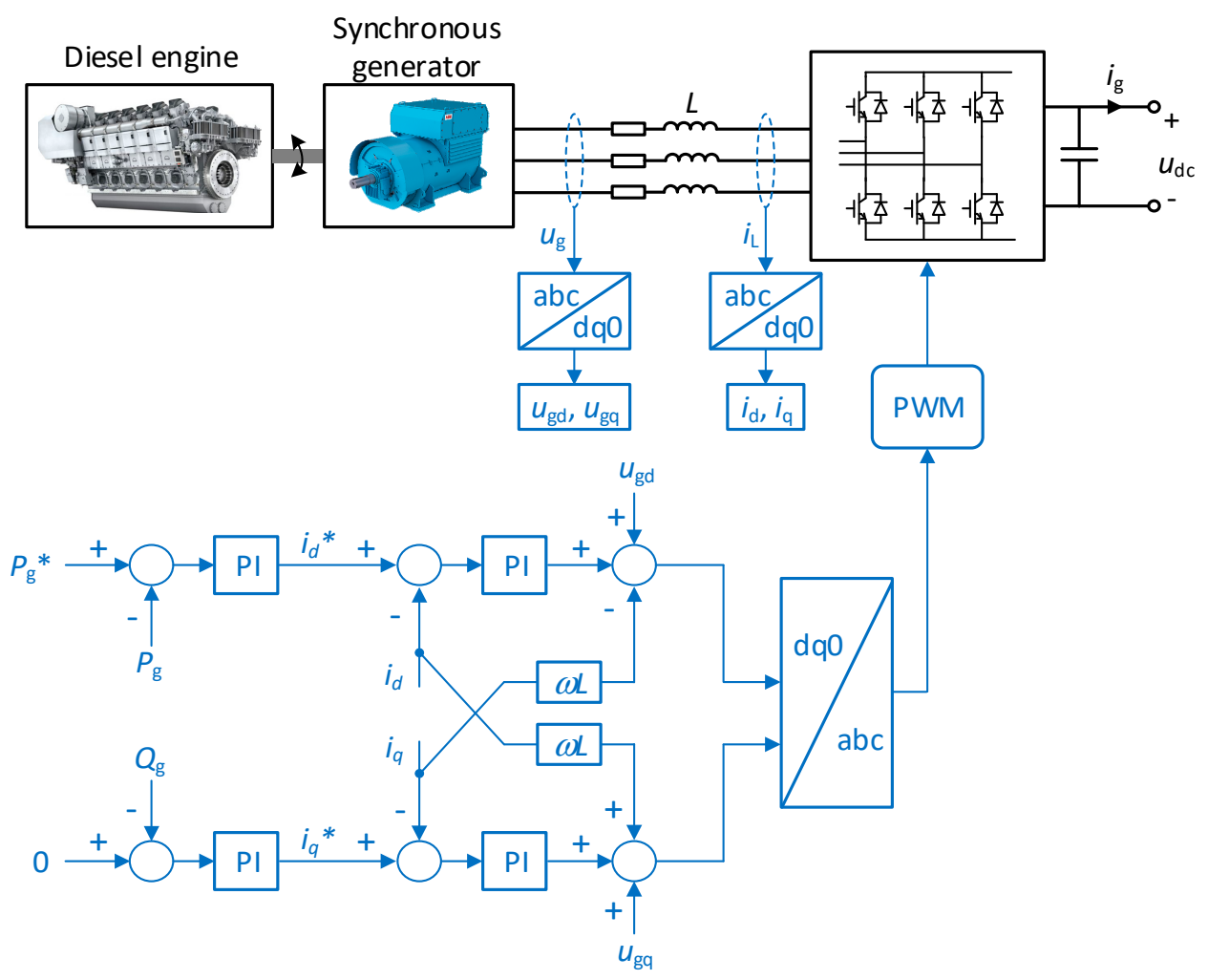

Figure 8. Control scheme of rectifier controller.

\section{Simulation Results}

In order to demonstrate the effectiveness of the proposed operation principle and coordinated control strategy, a $1 \mathrm{kV} / 270 \mathrm{~kW}$ DC SMG is simulated in Matlab/Simulink. The power component parameters and the parameters of the corresponding controllers are presented in Table 2. Two operation modes and the transition performances are studied in this section.

Table 2. Parameters of the studied DC SMG.

\begin{tabular}{|c|c|c|}
\hline Categories & Parameters & Values \\
\hline DC bus & nominal voltage & $1 \mathrm{kV}( \pm 10 \%)$ \\
\hline \multirow{12}{*}{ diesel generator } & rated power & $75 \mathrm{~kW}$ \\
\hline & nominal line-to-line voltage (RMS) & $440 \mathrm{~V}$ \\
\hline & nominal frequency & $50 \mathrm{~Hz}$ \\
\hline & $\mathrm{d}$-axis synchronous reactance $(\mathrm{Xd})$ & 0.875 p.u. \\
\hline & $\mathrm{d}$-axis transient reactance $\left(\mathrm{Xd}^{\prime}\right)$ & 0.19 p.u. \\
\hline & $\mathrm{d}$-axis subtransient reactance $\left(\mathrm{Xd}^{\prime \prime}\right)$ & 0.136 p.u. \\
\hline & $\mathrm{q}$-axis synchronous reactance $(\mathrm{Xq})$ & 0.1625 p.u. \\
\hline & $\mathrm{q}$-axis subtransient reactance $\left(\mathrm{Xq}^{\prime \prime}\right)$ & 0.135 p.u. \\
\hline & Stator leakage reactance $(\mathrm{Xl})$ & 0.0163 p.u. \\
\hline & d-axis transient time constant $\left(\mathrm{Tdo}^{\prime}\right)$ & $0.31 \mathrm{~s}$ \\
\hline & $\mathrm{d}$-axis subtransient time constant $\left(\mathrm{Tdo}^{\prime \prime}\right)$ & $0.027 \mathrm{~s}$ \\
\hline & q-axis subtransient time constant $\left(\mathrm{Tq}^{\prime \prime}\right)$ & $0.01 \mathrm{~s}$ \\
\hline \multirow{6}{*}{ rectifier and its controller } & DC-link capacitance & $3 \mathrm{mF}$ \\
\hline & synchronous inductance & $1.7 \mathrm{mH}$ \\
\hline & inductor resistance & $0.07 \Omega$ \\
\hline & switching frequency & $20 \mathrm{kHz}$ \\
\hline & inner current loop PI controller $K_{r p i}, K_{r i i}$ & $2 \mathrm{~V} / \mathrm{A}, 200 \mathrm{~V} / \mathrm{As}$ \\
\hline & outer power loop PI controller $K_{r p p}, K_{\text {rip }}$ & $1 \mathrm{~A} / \mathrm{W}, 100 \mathrm{~A} / \mathrm{Ws}$ \\
\hline
\end{tabular}


Table 2. Cont.

\begin{tabular}{ccc}
\hline Categories & Parameters & Values \\
\hline \multirow{2}{*}{ BESS } & nominal voltage & $600 \mathrm{~V}$ \\
& rated capacity & $50 \mathrm{Ah}$ \\
& maximum discharging current & $100 \mathrm{~A}$ \\
maximum charging current & $50 \mathrm{~A}$ \\
\hline bidirectional DC/DC & inductance & $1 \mathrm{mH}$ \\
converter and its & DC-link capacitance & $2 \mathrm{mF}$ \\
controller & switching frequency & $20 \mathrm{kHz}$ \\
& inner current loop PI controller $K_{d p i}, K_{d i i}$ & $0.6 \mathrm{~V} / \mathrm{A}, 20 \mathrm{~V} / \mathrm{As}$ \\
& outer voltage loop PI controller $K_{d p v}, K_{d i v}$ & $0.78 \mathrm{~A} / \mathrm{V}, 300 \mathrm{~A} / \mathrm{Vs}$ \\
& secondary controller $K_{s p}, K_{s i}$ & $0.01,30 \mathrm{~s}-1$ \\
& coefficient $m_{d i s c}$ & 0.05 \\
\hline
\end{tabular}

\subsection{All-Electric Mode}

In the all-electric mode, two diesel generators and rectifiers are disconnected from the system. This scenario is simulated to test the SoC-based droop control for the DC/DC converters. The total maximum output power of the two batteries is $120 \mathrm{~kW}$. Both batteries discharge to supply the load. The load demand is initially $100 \mathrm{~kW}$, increases to $120 \mathrm{~kW}$ at $\mathrm{t}=20 \mathrm{~s}$, and decreases to $80 \mathrm{~kW}$ at $\mathrm{t}=40 \mathrm{~s}$. The initial SoCs of the two batteries are $40 \%$ and $60 \%$, respectively.

The DC bus voltage and load current are shown in Figure 9. The DC bus voltage fluctuates when the load demand changes, and recovers to the nominal value within $0.015 \mathrm{~s}$. The discharging current of the two batteries is shown in Figure 10, and their ratio $i_{b 1}: i_{b 2}$ follows the ratio between the $\mathrm{SoC}$ of the two batteries, which is around 2:3. Note that, during $\mathrm{t}=20-40 \mathrm{~s}$, the load demand is slightly smaller than the maximum battery output power. Since the two batteries have a different initial SoC and are not fully discharged, the battery voltage is higher than the nominal value, which is the voltage when the battery reaches the minimum allowed SoC. Therefore, there are still differences between the two battery voltages. As battery 2 is forced to discharge at a maximum current, the difference in the battery voltage leads to a different battery current to satisfy the load demand. In this manner, the battery current does not follow the power sharing ratio. The SoC of the two batteries and SoC changing rate are shown in Figure 11. It is clear that battery 2 with a high $\mathrm{SoC}$ discharges faster than battery 1 with a low SoC, and the discharging speed follows the design.

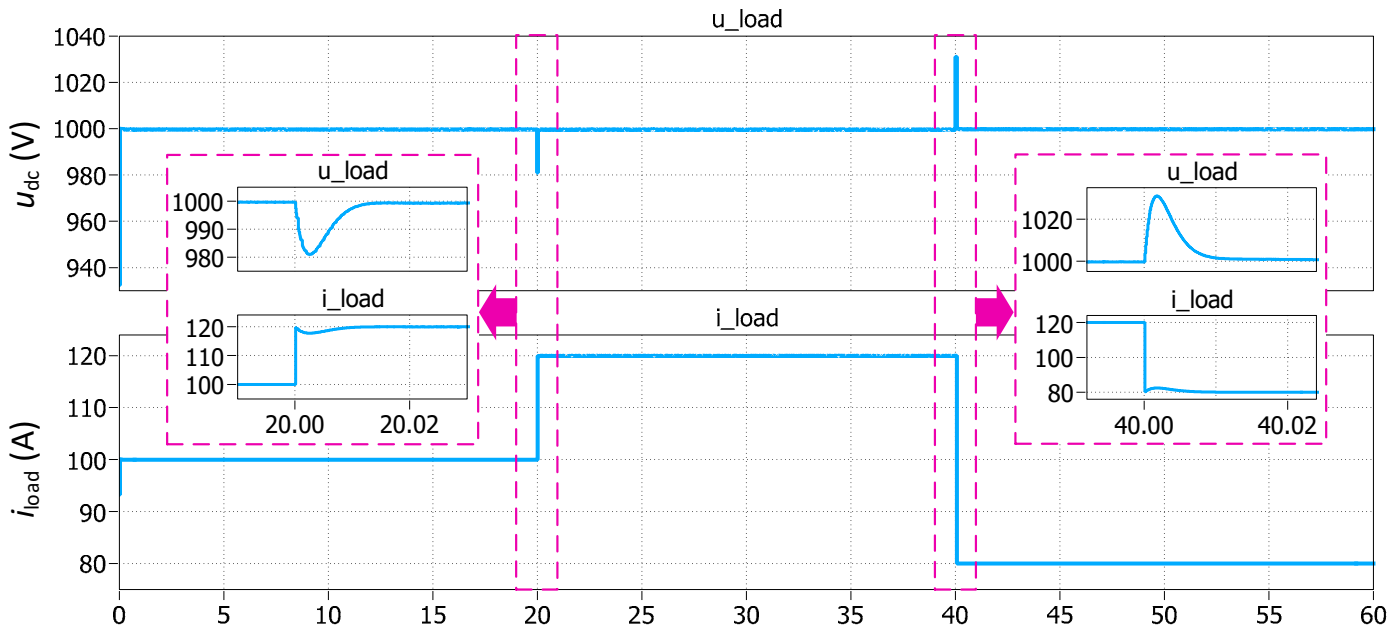

Figure 9. The DC bus voltage and load current in all-electric mode. 

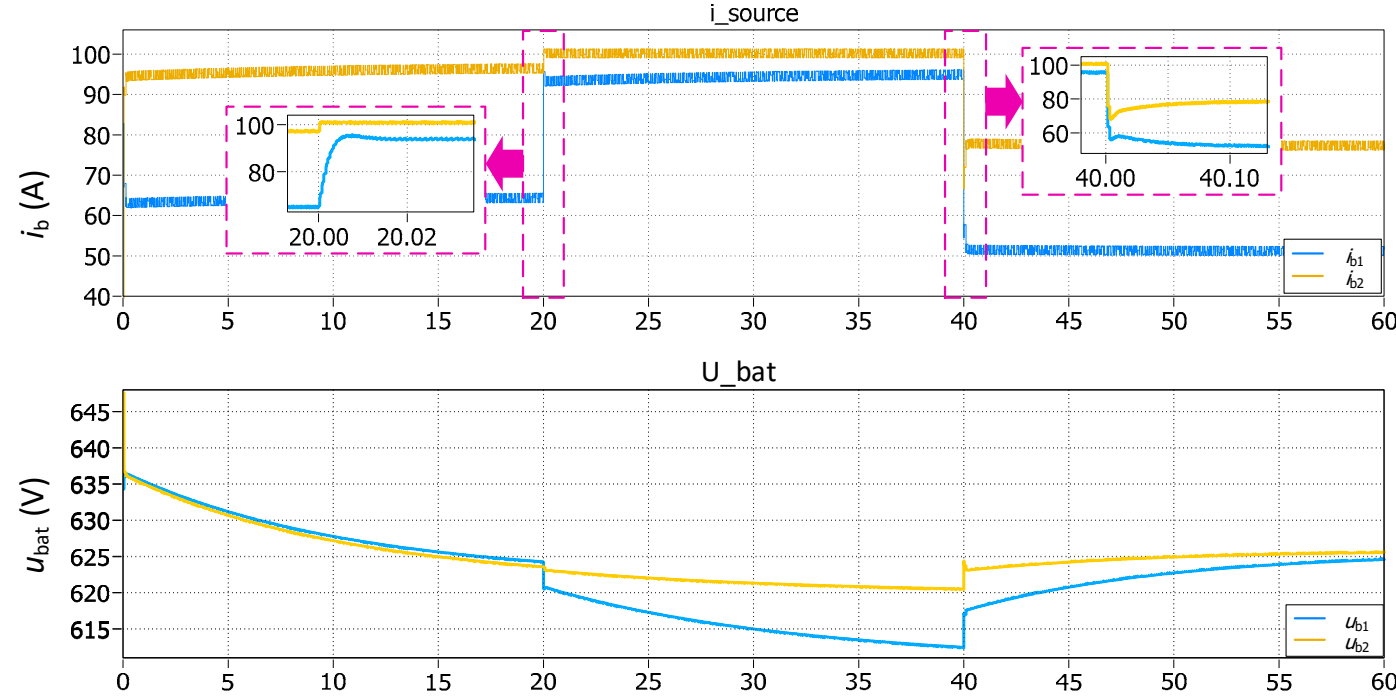

Figure 10. Battery current and voltage in all-electric mode.
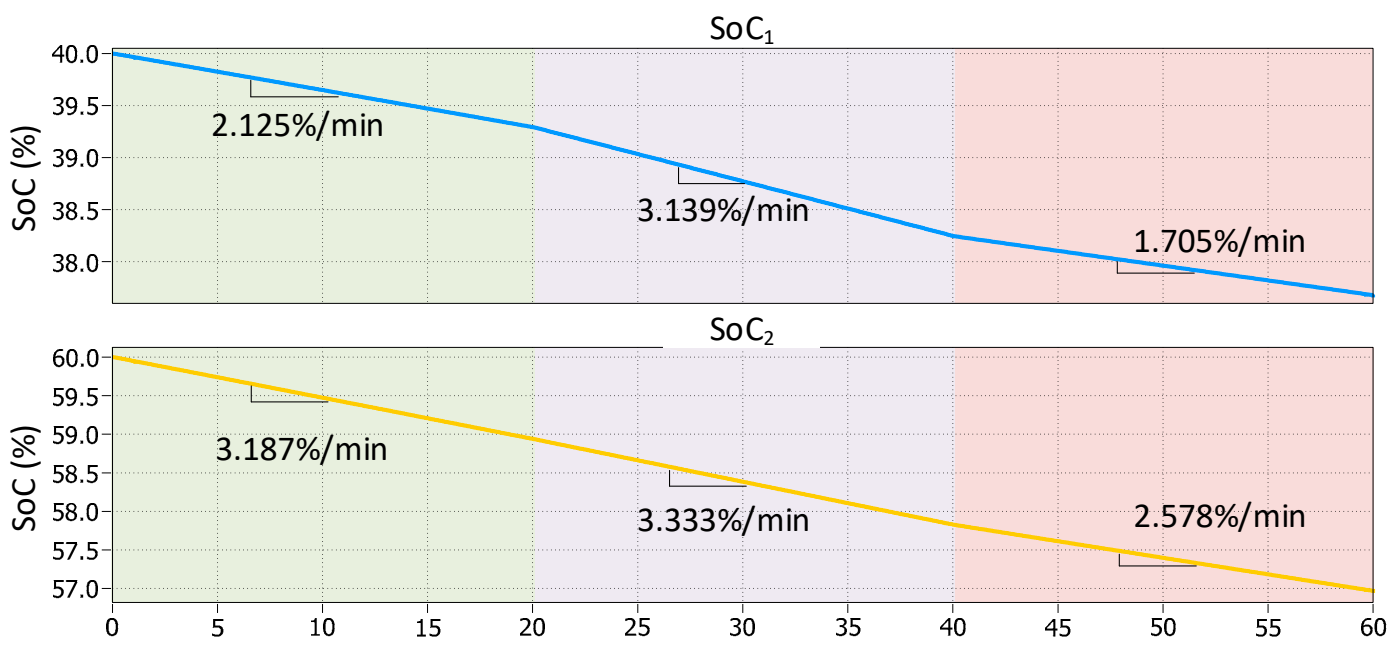

Figure 11. SoC of battery 1 and battery 2 in all-electric mode.

\subsection{Hybrid Mode}

In hybrid mode, both diesel generators and batteries are connected to the DC bus. Two scenarios, a light load with battery charging and a heavy load with battery discharging, are simulated to test the DC bus voltage control for rectifiers and the current control for DC/DC converters. The generators are designed to rotate at the nominal speed and produce the rated power. At $\mathrm{t}=0 \mathrm{~s}$, the load demand is $100 \mathrm{~kW}$, and the batteries are charged. At $\mathrm{t}=20 \mathrm{~s}$, the load demand increases to $200 \mathrm{~kW}$, and the batteries switch from charging to discharging. The initial SoCs of the two batteries are $40 \%$ and $60 \%$, respectively. According to the power sharing ratio in the DC/DC controllers, the charging power ratio during $0-20 \mathrm{~s}$ should be 3 to 2 , whereas the discharging power ratio during $20-40 \mathrm{~s}$ should be 2 to 3.

The simulation results are shown as follows. Figure 12 presents the DC bus voltage and load current. The DC bus voltage can be kept stable, and the voltage fluctuation when the load changes is within the acceptable range of $\pm 10 \%$ rated value. Figure 13 shows the rectifier current $\left(i_{g 1}, i_{g 2}\right)$ and battery current $\left(i_{b 1}, i_{b 2}\right)$. During the steady state, the rectifier current from the two generators are equal and constantly output the rated current of $75 \mathrm{~A}$; at $\mathrm{t}=0-20 \mathrm{~s}$, the two battery charging currents are $41.5 \mathrm{~A}$ and $27.5 \mathrm{~A}$, respectively, whereas at $\mathrm{t}=20-40 \mathrm{~s}$, the discharging currents are $34 \mathrm{~A}$ and $51 \mathrm{~A}$, respectively. The SoC of the two 
batteries are shown in Figure 14. The battery with a lower initial SoC charges faster and discharges slower than the battery with a higher initial $\mathrm{SoC}$, making it faster to reach the SoC balance between the two batteries.

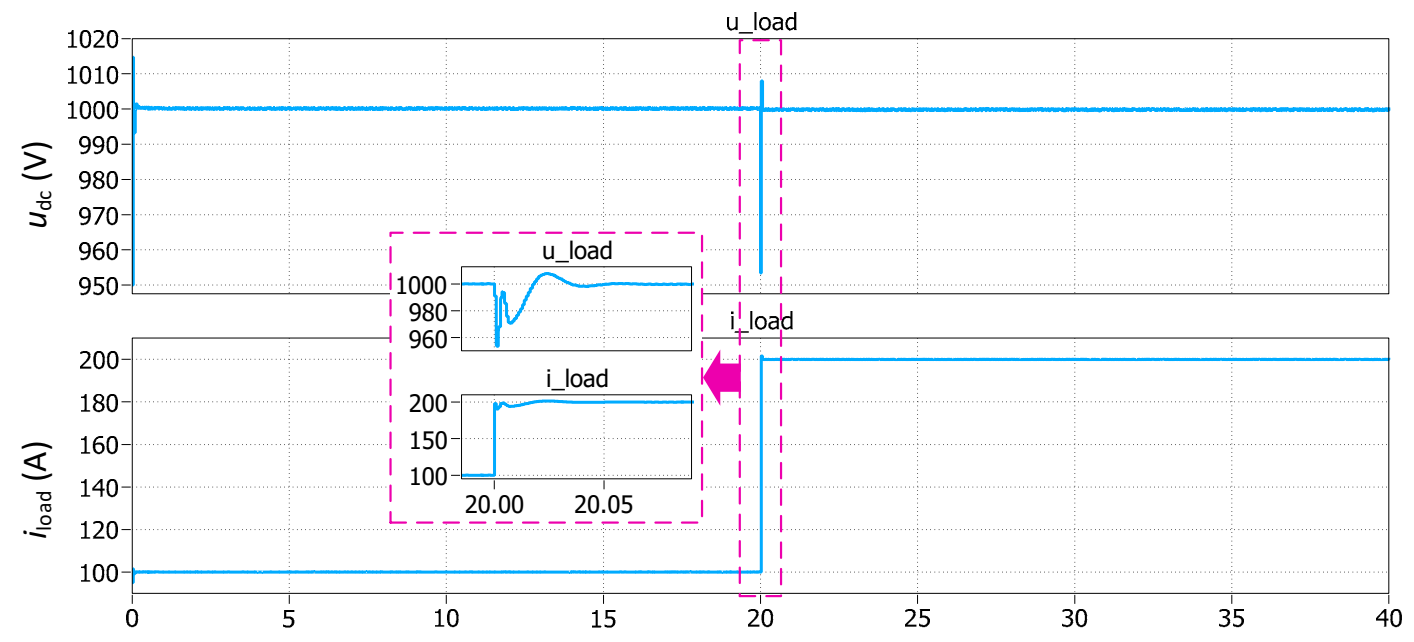

Figure 12. The DC bus voltage and load current in hybrid mode.
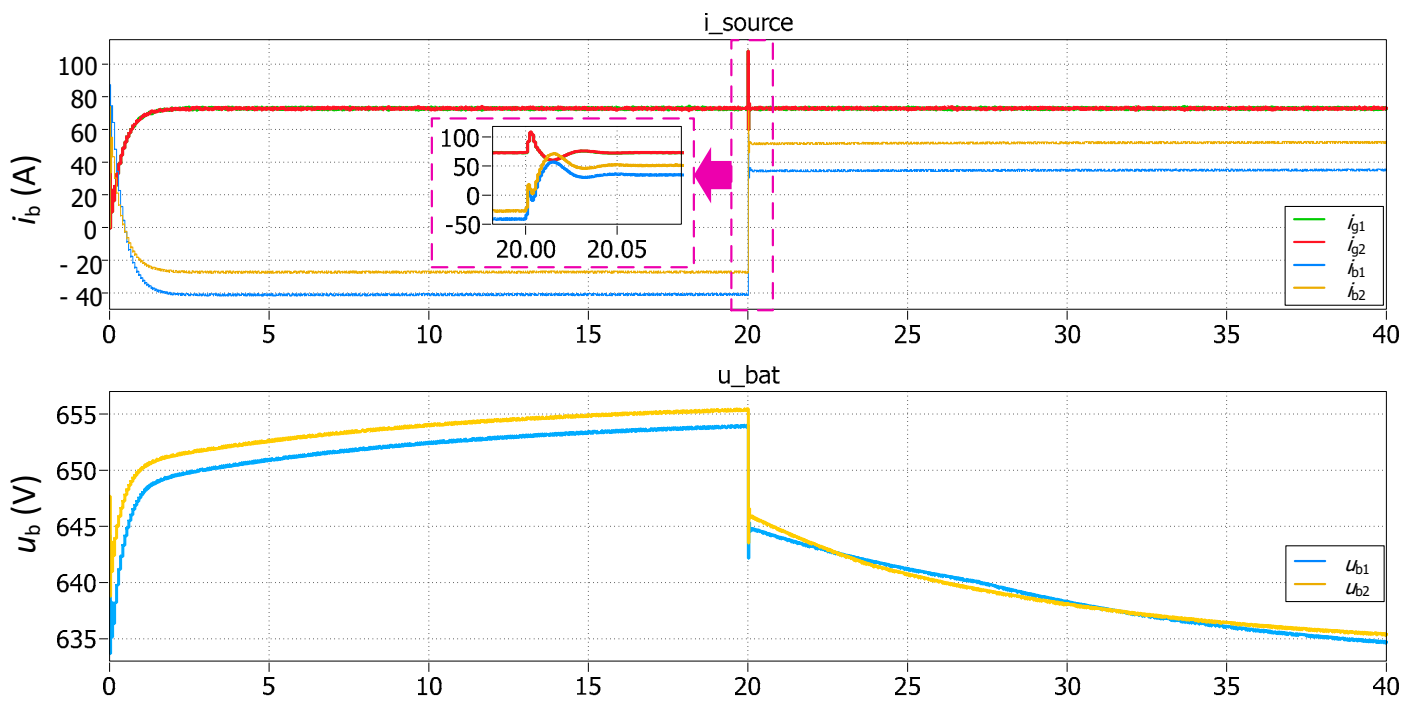

Figure 13. The rectifier, battery current, and battery voltage in hybrid mode.

\subsection{Mode Switching}

The switching between the all-electric mode and hybrid mode is simulated to test the transient states during mode switching. Four scenarios are simulated: (1) $t=0 \mathrm{~s}$, where the load demand is $100 \mathrm{~kW}$, which is lower than the power capacity of BESSs, therefore allowing for the system to operate in all-electric mode; (2) $t=20 \mathrm{~s}$, where the load increases to $125 \mathrm{~kW}$ and the system switches to hybrid mode; (3) $\mathrm{t}=40 \mathrm{~s}$, where the load further increases to $175 \mathrm{~kW}$ and is supplied by both generators and BESSs; (4) $\mathrm{t}=60 \mathrm{~s}$, where the load decreases back to $100 \mathrm{~kW}$, and the system switches to all-electric mode. The initial SoCs of the two BESSs are $40 \%$ and $60 \%$, respectively. 

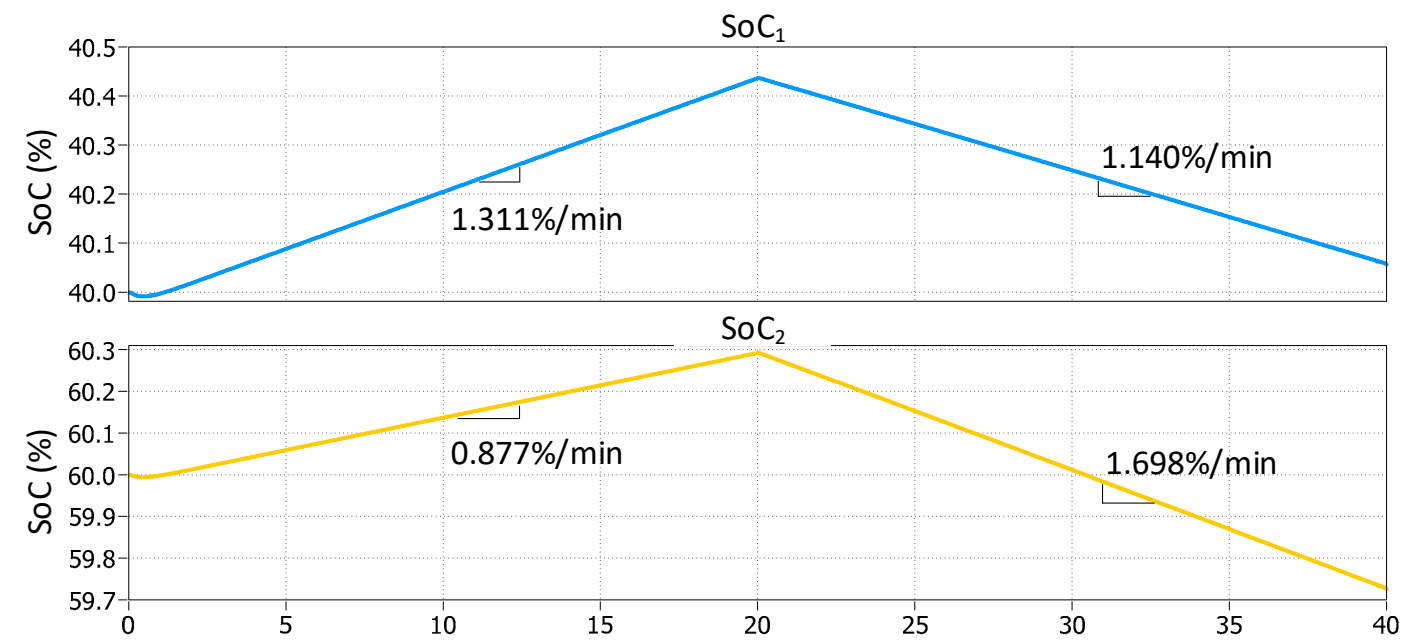

Figure 14. SoC of battery 1 and battery 2 in hybrid electric mode.

The simulation results are presented as follows. Figure 15 shows the DC bus voltage and the load current. The DC bus voltage is controlled at the rated value during the load change and mode switching. The output current of the rectifiers and DC/DC converters are shown in Figure 16. In scenario 1, two diesel generators are disconnected, and the rectifier currents in the generator side, $i_{\mathrm{g} 1}$ and $i_{\mathrm{g} 2}$, are zero. Two BESSs share the load, with the battery current of $i_{\mathrm{b} 1}=63 \mathrm{~A}$, and $i_{\mathrm{b} 2}=94.5 \mathrm{~A}$. At $\mathrm{t}=20 \mathrm{~s}$, the generators are connected and provide $150 \mathrm{~kW}$ during the steady state, exceeding the load demand. The surplus power is restored into the BESSs. The steady charging current of the two batteries are $18.5 \mathrm{~A}$ and $12.3 \mathrm{~A}$, respectively. Battery 1 with a lower SoC charges at a higher current. It takes approximately $2 \mathrm{~s}$ to reach the steady state, due to the relatively slow startup of synchronous generators. At $\mathrm{t}=40 \mathrm{~s}$, as the load demand increase, the BESSs switch from charging to discharging, and the battery 2 with a higher SoC provides more power than battery 1 . The discharging current of battery 1 and battery 2 are $18.5 \mathrm{~A}$ and $27.8 \mathrm{~A}$, respectively. At $\mathrm{t}=60 \mathrm{~s}$, the load demand decreases, and the two generators are disconnected, so the system switches back to all-electric mode. The two battery currents in this scenario are $63 \mathrm{~A}$ and 94.5 A, which is the same as the first scenario. The change in SoC is shown in Figure 17. The ratios of the charging and discharging speed between the two batteries in different load conditions follow the designed value.

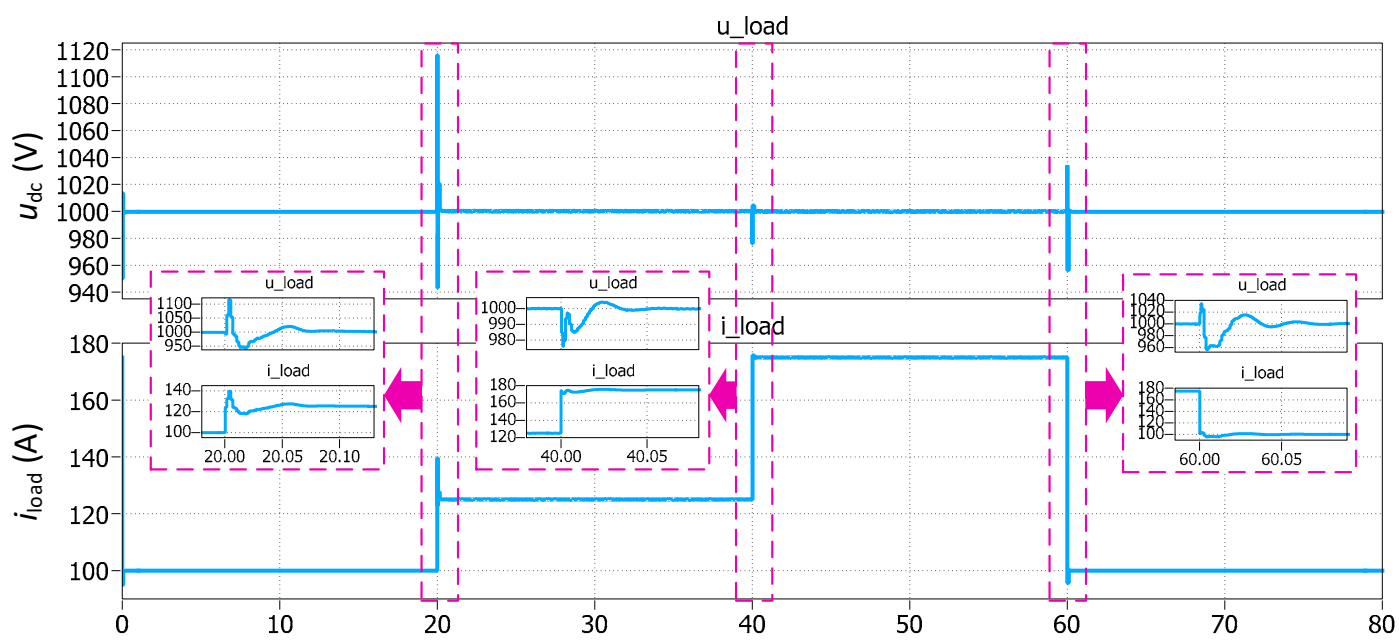

Figure 15. The DC bus voltage and load current during mode switching. 

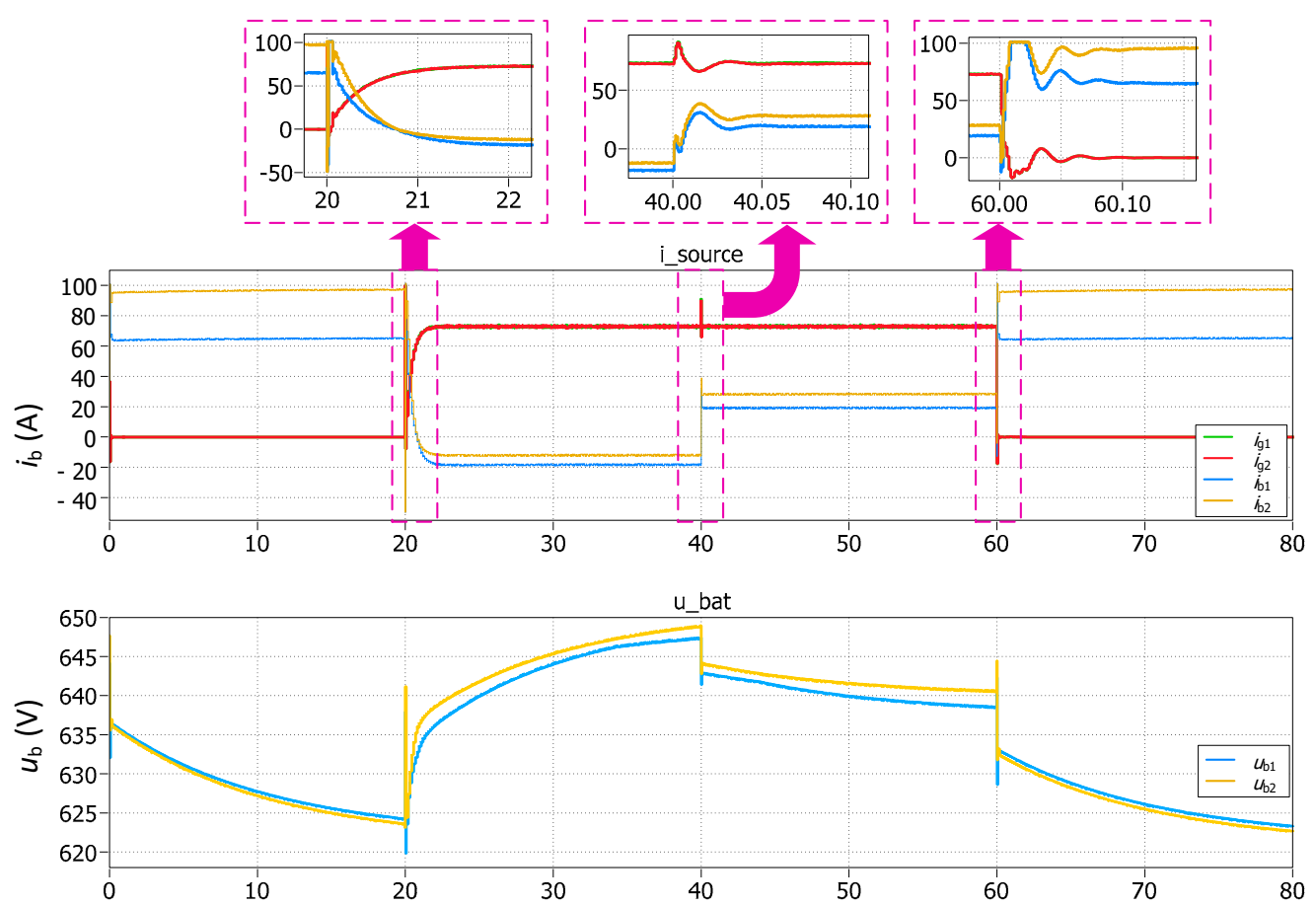

Figure 16. The rectifier, battery current, and battery voltage during mode switching.
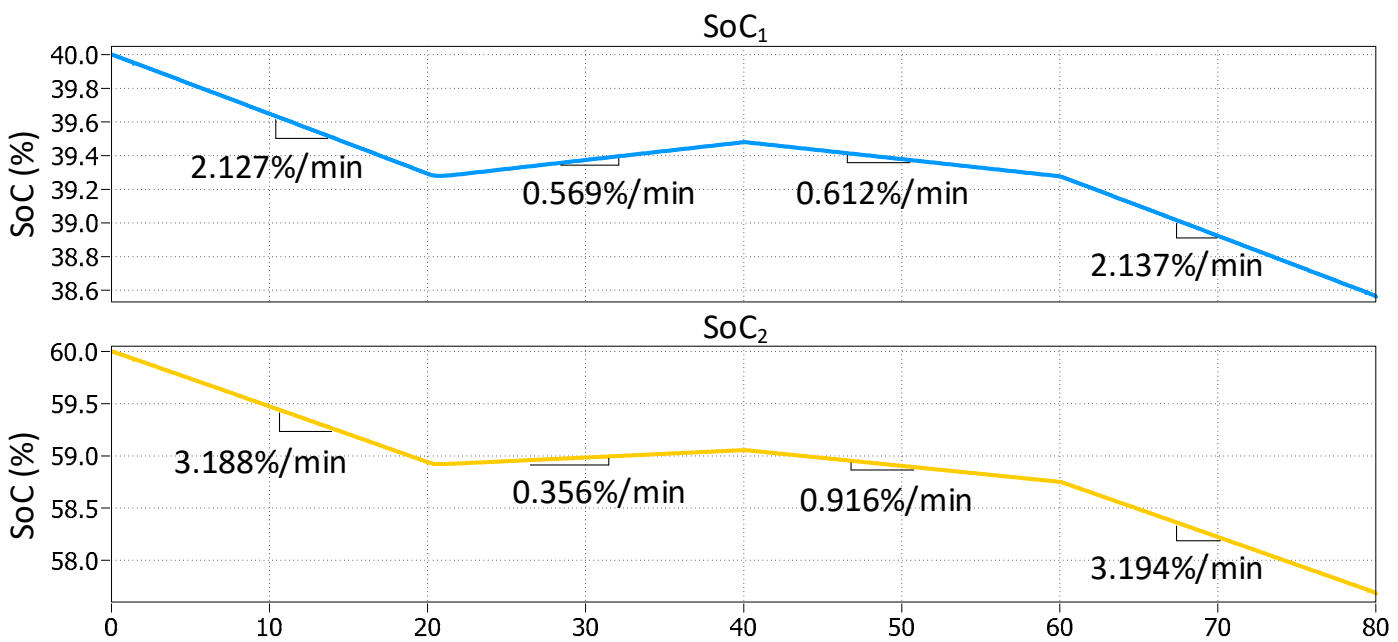

Figure 17. SoC of battery 1 and battery 2 during mode switching.

\section{Conclusions}

This paper presents a coordinated control scheme for a hybrid electric ship with both all-electric and hybrid operation modes. In the studied DC SMG, two governor-less diesel-engine-driven SGs and two BESSs are used as the power supply. Aiming at reaching the highest efficiency, the diesel generators are regulated by a constant power controller to provide the rated power. The BESSs are responsible for controlling the DC bus voltage by using a SoC-based adaptive droop control, where the power sharing ratio is continuously updated by the battery SoC and the charging/discharging states. In this manner, the power sharing ratio is proportional and inversely proportional to the SoC, respectively, and the overuse of batteries in the DC SMG can be avoided. For a comprehensive assessment, two operation modes of the investigated DC SMG, namely, all-electric and hybrid modes, and the mode switching between them, have been tested in the simulation studies, where several load conditions have been included. The simulation results show that the presented 
coordinated control enables the BESSs' charging and discharging according to the SoC ratio under all tested conditions, and that smooth mode switching can be achieved as well.

Author Contributions: Conceptualization, L.X.; methodology, L.X.; software, L.X. and B.W.; validation, L.X.; formal analysis, L.X. and Y.Y.; writing-original draft preparation, L.X.; writing-review and editing, L.X., Y.Y. and B.W.; supervision, J.M.G. and J.V.; project administration, J.M.G.; funding acquisition, J.M.G. All authors have read and agreed to the published version of the manuscript.

Funding: This research was funded by a Villum Investigator from The Villum Fonden, grant number 25920.

Institutional Review Board Statement: Not applicable.

Informed Consent Statement: Not applicable.

Data Availability Statement: Not applicable.

Acknowledgments: This work was supported by VILLUM FONDEN under the VILLUM Investigator Grant (No. 25920): Center for Research on Microgrids (CROM); www.crom.et.aau.dk.

Conflicts of Interest: The authors declare no conflict of interest.

\section{References}

1. Castellan, S.; Menis, R.; Tessarolo, A.; Luise, F.; Mazzuca, T. A review of power electronics equipment for all-electric ship MVDC power systems. Int. J. Electr. Power Energy Syst. 2018, 96, 306-323. [CrossRef]

2. Sulligoi, G.; Vicenzutti, A.; Menis, R. All-electric ship design: From electrical propulsion to integrated electrical and electronic power systems. IEEE Trans. Transp. Electrif. 2016, 2, 507-521. [CrossRef]

3. Xiao, Z.-X.; Li, H.-M.; Fang, H.-W.; Guan, Y.-Z.; Liu, T.; Hou, L.; Guerrero, J.M. Operation Control for Improving Energy Efficiency of Shipboard Microgrid Including Bow Thrusters and Hybrid Energy Storages. IEEE Trans. Transp. Electrif. 2020, 6, 856-868. [CrossRef]

4. Faddel, S.; El Hariri, M.; Mohammed, O. Intelligent Control Framework for Energy Storage Management on MVDC Ship Power System. In Proceedings of the 2018 IEEE International Conference on Environment and Electrical Engineering and 2018 IEEE Industrial and Commercial Power Systems Europe (EEEIC/I\&CPS Europe), Palermo, Italy, 12-15 June 2018; pp. 1-6.

5. Domaschk, L.N.; Ouroua, A.; Hebner, R.E.; Bowlin, O.E.; Colson, W.B. Coordination of large pulsed loads on future electric ships. IEEE Trans. Magn. 2007, 43, 450-455. [CrossRef]

6. Zahedi, B.; Norum, L.E. Modeling and simulation of all-electric ships with low-voltage DC hybrid power systems. IEEE Trans. Power Electron. 2013, 28, 4525-4537. [CrossRef]

7. Zhou, Z.; Camara, M.B.; Dakyo, B. Coordinated power control of variable-speed diesel generators and lithium-battery on a hybrid electric boat. IEEE Trans. Veh. Technol. 2017, 66, 5775-5784. [CrossRef]

8. Bo, T.I.; Johansen, T.A. Battery Power Smoothing Control in a Marine Electric Power Plant Using Nonlinear Model Predictive Control. IEEE Trans. Control Syst. Technol. 2017, 25, 1449-1456. [CrossRef]

9. Bellache, K.; Camara, M.B.; Dakyo, B. Transient power control for diesel-generator assistance in electric boat applications using supercapacitors and batteries. IEEE J. Emerg. Sel. Top. Power Electron. 2018, 6, 416-428. [CrossRef]

10. Eldeeb, H.H.; Mohammed, O.A. Control and Voltage Stability of A Medium Voltage DC Micro-Grid Involving Pulsed Load. In Proceedings of the 2018 IEEE International Conference on Environment and Electrical Engineering and 2018 IEEE Industrial and Commercial Power Systems Europe, EEEIC/I and CPS Europe 2018, Palermo, Italy, 12-15 June 2018; pp. 2-7.

11. Kulkarni, S.; Santoso, S. Impact of pulse loads on electric ship power system: With and without flywheel energy storage systems. In Proceedings of the 2009 IEEE Electric Ship Technologies Symposium, Baltimore, MD, USA, 20-22 April 2009 ; pp. 568-573.

12. Farahani, K.M. Modeling and Analysis of a Flywheel Energy Storage System for Voltage Regulation. IEEE Trans. Ind. Appl. 2012, $42,42-52$.

13. Tang, Y.; Khaligh, A. Bidirectional hybrid battery/ultracapacitor energy storage systems for next generation MVDC shipboard power systems. In Proceedings of the 2011 IEEE Vehicle Power and Propulsion Conference, Chicago, IL, USA, 6-9 September 2011; pp. 1-6.

14. Elsayed, A.T.; Mohammed, O.A. A comparative study on the optimal combination of hybrid energy storage system for ship power systems. In Proceedings of the 2015 IEEE Electric Ship Technologies Symposium (ESTS), Alexandria, VA, USA, 21-24 June 2015; pp. 140-144.

15. Xiao, Z.; Tianli, Z.; Huaimin, L.; Guerrero, J.M.; Su, C.-L.; Vasquez, J.C. Coordinated Control of a Hybrid-Electric-Ferry Shipboard Microgrid. IEEE Trans. Transp. Electrif. 2019, 5, 828-839.

16. Perkins, D.; Vu, T.; Vahedi, H.; Edrington, C.S. Distributed power management implementation for zonal MVDC ship power systems. In Proceedings of the IECON 2018-44th Annual Conference of the IEEE Industrial Electronics Society, Washington, DC, USA, 20-23 October 2018; Volume 1, pp. 3401-3406. 
17. Hossain, M.R.; Ginn, H.L. Real-Time Distributed Coordination of Power Electronic Converters in a DC Shipboard Distribution System. IEEE Trans. Energy Convers. 2017, 32, 770-778. [CrossRef]

18. Kankanala, P.; Srivastava, S.C.; Srivastava, A.K.; Schulz, N.N. Optimal control of voltage and power in a multi-zonal MVDC shipboard power system. IEEE Trans. Power Syst. 2012, 27, 642-650. [CrossRef]

19. Birudula, A.; Selvaraj, R.; Desingu, K.; Chelliah, T.; Upadhyayula, R.S. A Coordinated Control Strategy for Diesel Electric Tugboat System for Improved Fuel Economy. IEEE Trans. Ind. Appl. 2020, 56, 5439-5451.

20. Zahedi, B.; Norum, L.E.; Ludvigsen, K.B. Optimized efficiency of all-electric ships by dc hybrid power systems. J. Power Sources 2014, 255, 341-354. [CrossRef]

21. Zahedi, B.; Norum, L.E.; Ludvigsen, K.B. Optimization of fuel consumption in shipboard power systems. In Proceedings of the IECON 2013-39th Annual Conference of the IEEE Industrial Electronics Society, Vienna, Austria, 10-13 November 2013; pp. $1124-1129$.

22. Shajari, Z. Operation Management for Next-Generation of MVDC Shipboard Microgrids. In Proceedings of the 2020 International Conference on Smart Energy Systems and Technologies (SEST), Istanbul, Turkey, 7-9 September 2020; pp. 7-12.

23. Jin, Z.; Meng, L.; Guerrero, J.M.; Han, R. Hierarchical control design for a shipboard power system with DC distribution and energy storage aboard future more-electric ships. IEEE Trans. Ind. Inform. 2018, 14, 703-714. [CrossRef]

24. Jin, Z.; Meng, L.; Vasquez, J.C.; Guerrero, J.M. Frequency-division power sharing and hierarchical control design for DC shipboard microgrids with hybrid energy storage systems. In Proceedings of the 2017 IEEE Applied Power Electronics Conference and Exposition (APEC), Tampa, FL, USA, 26-30 March 2017; pp. 3661-3668.

25. IEEE Standards Association. IEEE Recommended Practice for $1 \mathrm{kV}$ to $35 \mathrm{kV}$ Medium-Voltage DC Power Systems on Ships; IEEE Industry Applications Society: New York, NY, USA, 2010.

26. Dong, D.; Pan, Y.; Lai, R.; Wu, X.; Weeber, K. Active Fault-Current Foldback Control in Thyristor Rectifier for DC Shipboard Electrical System. IEEE J. Emerg. Sel. Top. Power Electron. 2017, 5, 203-212. [CrossRef]

27. Kalla, U.K.; Singh, B.; Murthy, S.S. Green Controller for Efficient Diesel Engine Driven Single-Phase SEIG Using Maximum Efficiency Point Operation. IEEE Trans. Ind. Electron. 2017, 64, 264-274. [CrossRef]

28. Lu, X.; Sun, K.; Guerrero, J.M.; Vasquez, J.C.; Huang, L. Double-quadrant state-of-charge-based droop control method for distributed energy storage systems in autonomous DC Microgrids. IEEE Trans. Smart Grid 2015, 6, 147-157. [CrossRef]

29. Guerrero, J.M.; Vasquez, J.C.; Matas, J.; De Vicuña, L.G.; Castilla, M. Hierarchical control of droop-controlled AC and DC microgrids-A general approach toward standardization. IEEE Trans. Ind. Electron. 2011, 58, 158-172. [CrossRef]

30. Mukherjee, N.; Strickland, D. Control of Cascaded DC-DC Converter-Based Hybrid Battery Energy Storage Systems-Part I: Stability Issue. IEEE Trans. Ind. Electron. 2016, 63, 2340-2349. [CrossRef]

31. Pavlovic, T.; Bjazic, T.; Ban, Z. Simplified Averaged Models of DC—DC Power Converters Suitable for Controller Design and Microgrid Simulation. IEEE Trans. Power Electron. 2013, 28, 3266-3275. [CrossRef]

32. Kavil Kambrath, J.; Wang, Y.; Yoon, Y.J.; Aaron Alexander, A.; Liu, X.; Wilson, G.; Gajanayake, C.J.; Gupta, A.K. Modeling and Control of Marine Diesel Generator System with Active Protection. IEEE Trans. Transp. Electrif. 2017, 4, 249-271. [CrossRef] 